\title{
Biological Control of Heavy Metal Pollutants in Water by Salvinia molesta
}

\author{
Sweta Kumari ${ }^{1}$, Baidyanath Kumar ${ }^{2 *}$ and Rimjhim Sheel ${ }^{1}$ \\ ${ }^{1}$ Department of Botany, Ganga Devi Mahila College (Magadh University), \\ Kankarbagh, Patna, India \\ ${ }^{2}$ Visiting Professor, Dept. of Biotechnology, Patna Science College, Patna, India
}

*Corresponding author

\author{
A B S T R A C T
}

Heavy metals severely affect the quality of water. Species of Salvinia are regarded as potent hyperaccumulators of heavy metals. Biotechnology will play a promising role in the development of new hyper accumulators by transferring metal hyper accumulating genes

Keywords

Heavy metals, phytoremediation, bioaccumulation, hyperaccumulators, Salvinia molesta.

Article Info

Accepted:

20 March 2017

Available Online:

10 April 2017 from low biomass wild species to the higher biomass producing cultivated species. Heavy metal toxicity and the danger of their bioaccumulation in the food chain represent major environmental and health problems. A very promising, environmental-friendly and cost effective alternative is plant based Biological control of heavy metal pollutants. Salvinia molesta holds a distinct position because of high productivity and tolerance to a wide range of temperatures. In the present investigation Biological control of Lead and Mercury contaminants of water by $S$. molesta was studied. The results showed that Salvinia molesta was able remove both Lead and Mercury from the polluted water. The percentage reduction in Lead and Mercury concentrations in the experimental water varied greatly at different concentration of both contaminants in the two aquaria used. It was found that at some points in the experiment involving mixed concentration of iron and chromium, there were preferences on accumulation of metals by Salvinia molesta. Lead was initially more accumulated by Salvinia molesta (up to $85 \%$ ). As the concentration of contaminants increased, at high concentrations, Mercury was recorded to have been accumulated more in Salvinia molesta (up to 74\%).

\section{Introduction}

Salvinia Guettard is a Weed of National Significance and is regarded as one of the worst weeds because of its invasiveness, potential for spread, and economic and environmental impacts. It is an aquatic weed that can choke waterways. It floats on still or slow-moving water and can grow rapidly to cover the entire water surface with a thick mat of vegetation. This shades out any submerged plant life and impedes oxygen exchange, making the water unsuitable for fish and other animals. The infestation of Salvinia reduces the natural beauty and biodiversity of wetlands and block irrigation, cause flooding, pollute drinking water, and prevent recreational activities such as swimming, fishing and boating.

Water pollution is a major global problem and it is leading worldwide cause of deaths and diseases. The strongest water pollutants are 
insecticides, pollutants from livestock operations, volatile organic compounds, food processing waste and chemical waste. Heavy metals are the most dangerous type of chemicals since they are serious health hazard. The most common heavy metal contaminants are: Cadmium (Cd), Chromium $(\mathrm{Cr})$, Copper $(\mathrm{Cu})$, Mercury $(\mathrm{Hg})$, Lead $(\mathrm{Pb})$, Nickel (Ni) and Zinc (Zn). Industrial effluents are the major source of heavy metal pollution. Chromium and Copper are the principal components and have led to the destruction of various aquatic ecosystems. Phytoremediation of heavy metals by macrophytes has largely been reviewed by Dushenkov et al., 1995; Rai et al., 1995; Schneider and Rubio, 1999; Skinner et al., 2007; Olguín et al., 2002; Sune et al., 2007; Sánchez-Galván et al., 2008; Xu et al., 2009; Banerjee and Sarkar, 1997; Hoffman et al., 2004; Espinoza- uinones et al., 2005; Mukherjee and Kumar, 2005; Molisani et al.,2006; Sune et al., 2007; Olguin et al., 2005; Heike Bradl, 2005; Sweta kumara et al., (2016) etc.

The bioremediation (phytoremediation) of heavy metals viz. Lead and Mercury in Bihar (India) has not been thoroughly investigated and hence the present study was undertaken to evaluate the efficacy of Salvinia molesta to accumulate these heavy metals.

\section{Materials and Methods}

The plants of Salvinia molesta were washed several times in tap water and finally in deionized distilled water to remove the impurities periphyton, dust and sediment particles. The material was stored in polythene bags, at the same time the water samples around the plants were collected randomly and brought to laboratory. The temperature of water at the time of sampling was recorded.

All individual plant samples were again washed with distilled deionized water in laboratory.
The molar stock solution of heavy metal salts viz., Mercuric chloride and Lead chloride was prepared by dissolving $271.52 \mathrm{~g}$ and $278.1 \mathrm{~g}$ respectively in $1000 \mathrm{ml}$ of distilled water separately. From these molar stock solution four different concentrations of each of the heavy metal salt solution such as $25 \mathrm{mg} / \mathrm{l}, 50$ $\mathrm{mg} / \mathrm{l}, 75 \mathrm{mg} / \mathrm{l}$ and $100 \mathrm{mg} / \mathrm{l}$ were prepared separately.

The plants of S. molesta of more or less uniform size and equal number were treated with different concentration of each of the heavy metal salts separately in aquarium. The setup was left undisturbed in a shaded area for 10 days. After 10 days of treatment with heavy metal salts the plants were harvested from each container separately. Plants were then washed with distilled water to remove excess salts present around it. With the help of tissue paper the excess water was removed from the plant. The treated plants were then analysed.

After 10 days of treatment each plant sample from control and plants treated with different concentrations heavy metal salts were carefully taken and the fresh weight of the plant samples were analysed using a monobalance.

The fresh plants from both the control and plants treated with different concentrations of heavy metal salts viz., 25\%, $50 \%, 75 \%$ and $100 \%$ were taken and dried first in sun light for 10 days and then in hot air oven at $110^{\circ} \mathrm{C}$ for 12 hours. The dry weight of the samples were analysed using a monobalance.

The dried samples of Salvinia molesta were weighed accurately and dissolved in $\mathrm{HNO}_{3}$ and $\mathrm{HClO}_{4}$ (in the ratio 3:1). The resulting mixtures were evaporated to dryness and extracted with distilled, deionized water. The solutions were heated to boiling and filtered. The volumes of the diluted sample were made 
to $100 \mathrm{~mL}$ each. $1.0 \mathrm{~L}$ water sample was heated to reduce the volume, acidified and total $100 \mathrm{~mL}$ volume was made. The metal ion concentrations in all the samples were analyzed by Atomic Absorption Spectrometer. The results obtained have been presented in Table-1 and 2; Fig- 1 and 2.

\section{Results and Discussion}

From the results (Table- 1 and 2) it is evident that after 10 days of treatment the all the plants of Salvinia molesta showed a substantial amount of accumulation of Mercury and Lead in their tissues. The dried samples were powdered and the ash was digested and the amount of metal accumulation was analysed using Atomic Absorption Spectrophotometer.

In the present investigation it was found that the bioaccumulation of heavy metals increased with increasing their concentrations. At $100 \%$ maximum accumulation of heavy metals was noticed in all the plants of
Salvinia molesta. S. molesta showed 17575ppm Mercury and, 17675ppm Lead in their tissues at $100 \%$ concentration. The present findings gain support from the work of Sweta kumara et al. (2016) who also reported a more or less similar results for bioaccumulation of heavy metals by three species of Salvinia viz. S. natans, S. molesta and $S$. auriculata

In the present investigation it was found that at some points in the experiment involving mixed concentration of Mercury and Lead, there were preferences on accumulation of metals by Salvinia molesta. Lead was initially more accumulated by Salvinia molesta (up to $85 \%$ ). As the concentration of contaminants increased, at high concentrations, Mercury was recorded to have been accumulated more in Salvinia molesta (up to 74\%).

Therefore, from the results it can be concluded that Salvinia molesta is more efficient in accumulating highest amounts of these two heavy metals.

Table.1 Bioaccumulation of Mercury (in ppm) by Salvinia molesta

\begin{tabular}{|l|l|}
\hline Conc. of $\mathrm{Hg}(\%)$ & S. molesta \\
\hline Control & 0 \\
\hline 25 & $7675 \pm 1.63$ \\
\hline 50 & $11765 \pm 1.45$ \\
\hline 75 & $14550 \pm 1.66$ \\
\hline 100 & $17575 \pm 1.63$ \\
\hline
\end{tabular}

Table.2 Bioaccumulation of Lead (in ppm) by Salvinia molesta

\begin{tabular}{|l|l|}
\hline $\begin{array}{l}\text { Conc. of } \\
\text { Pb }(\%)\end{array}$ & S. molesta \\
\hline Control & 0 \\
\hline 25 & $7675 \pm 1.62$ \\
\hline 50 & $12545 \pm 1.40$ \\
\hline 75 & $14550 \pm 1.61$ \\
\hline 100 & $17675 \pm 1.61$ \\
\hline
\end{tabular}


Fig.1 Bioaccumulation of Mercury (in ppm) by Salvinia molesta

1, Control; 2, 25\%; 3, 50\%; 4, 75\%; 5, 100\%

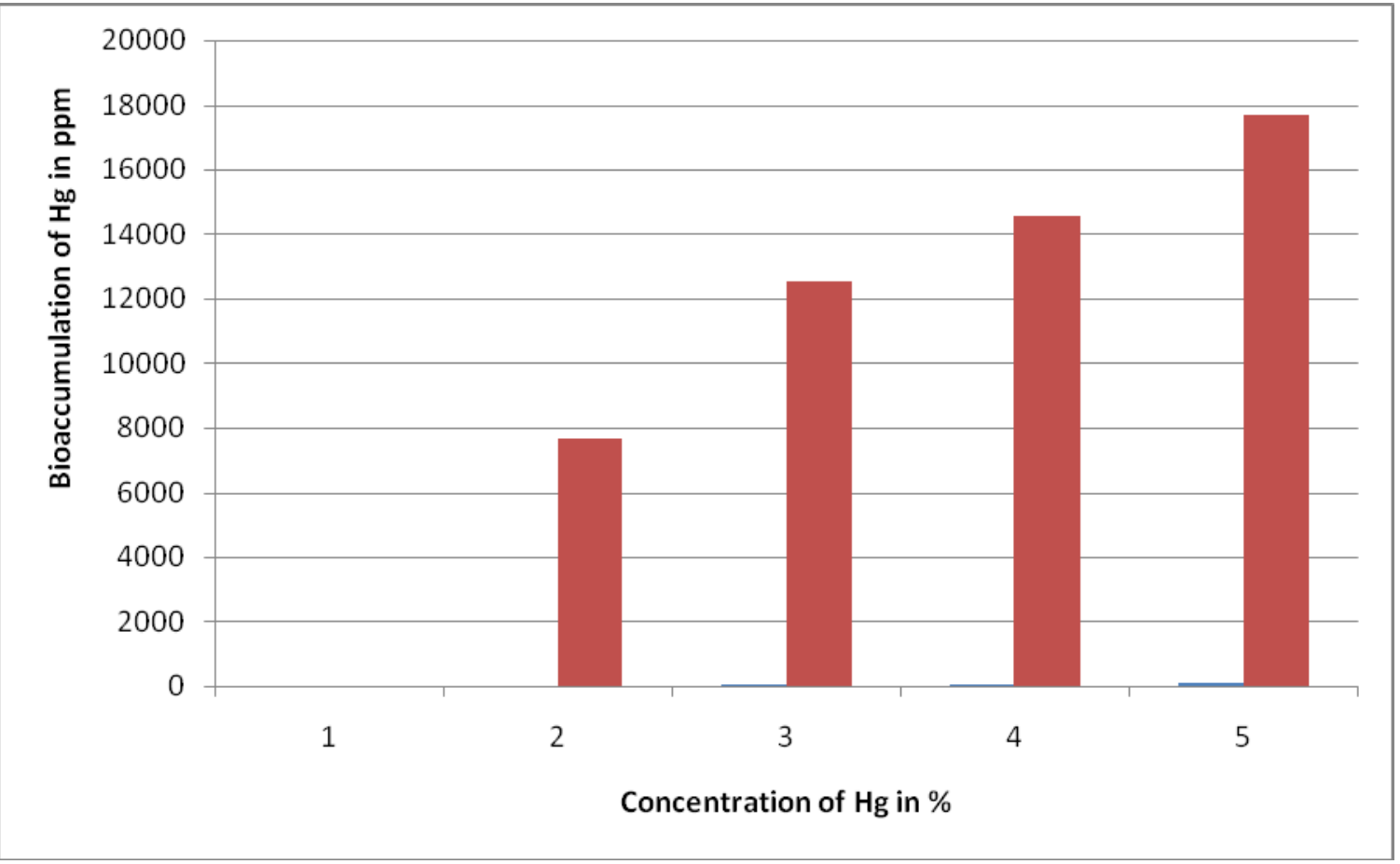

Fig.2 Bioaccumulation of Lead (in ppm) by Salvinia molesta

1, Control; 2, 25\%; 3, 50\%; 4, 75\%; 5, 100\%

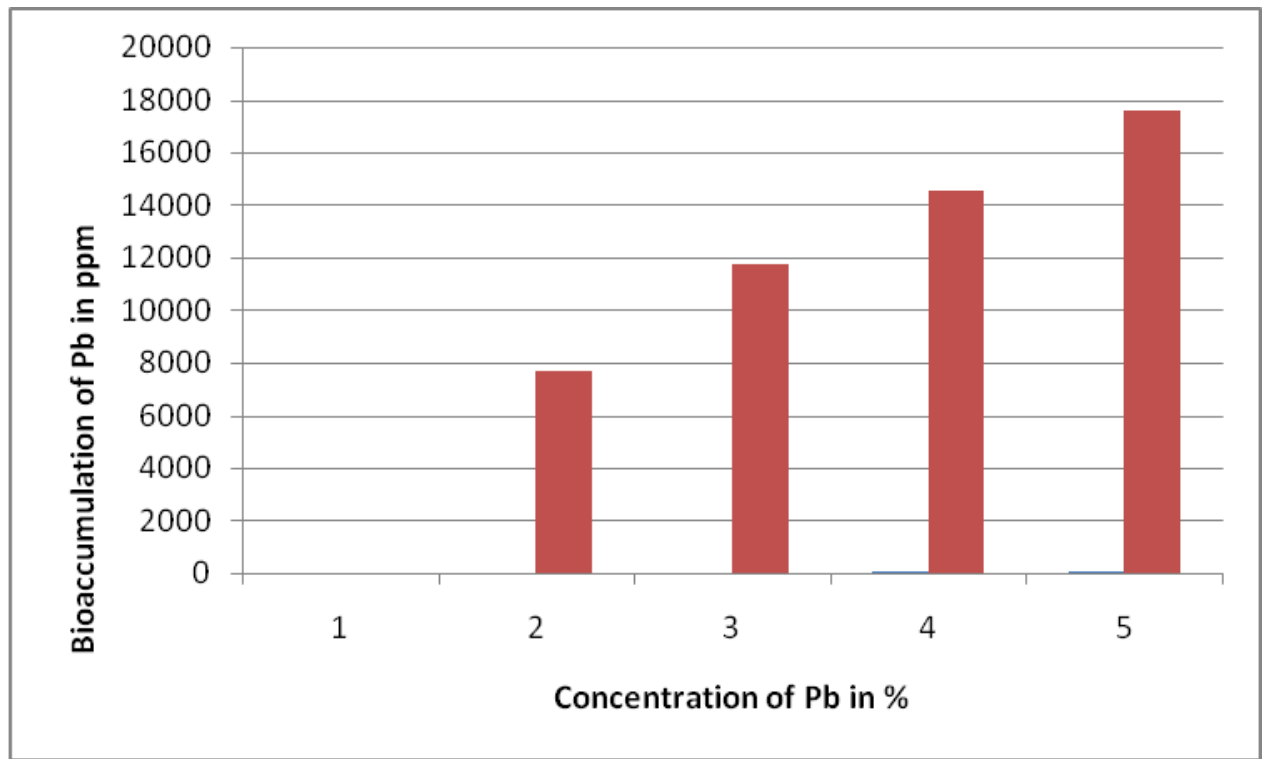

The results obtained in the experimental study prove the fact that the plants of S. molesta have the innate capacity for the accumulation of appreciable quantities of heavy metals.
Salvinia molesta performs better Rhizofiltration to absorb, concentrate, and precipitate toxic metals from contaminated water. They are natural hyper accumulators of 
many heavy and toxic metals. Therefore they can be effectively employed in phytoremediation of polluted water bodies. Initially, suitable plants with stable root systems can be supplied with contaminated water to acclimate the plants. Then these plants can be transferred to the contaminated site to collect the contaminants, and once the roots are saturated, they can be harvested. Rhizofiltration allows in-situ treatment, minimizing disturbance to the environment. The only drawback of using these plants for phytoremediation is that the species of Salvinia are invasive. They rapidly colonise aquatic ecosystems and reduce the populations of native plants. However, species of Salvinia have a high biomass and can effectively be used for the production of biofuels, especially bio-ethanol and biomethanol.

\section{Acknowledgement}

The author is grateful to Dr. Baidyanath Kumar, Visiting Professor, Department of Biotechnology, Patna Science College (Patna University), Patna for providing necessary suggestions.

\section{References}

Banerjee, G., Sarker, S. (1997): The role of Salvinia rotundifolia in scavenging aquatic $\mathrm{Pb}$ (II) pollution: a case study. Bioprocess Engineering 17,295-300.

Dushenkov, V.P., Nandakumar, B.A., Motto, H., Raskin, I., (1995): Rhizofilltration: The use of plants to remove heavy metals from aqueous streams. Environmental Science and Technology 29, 1239-1241.

Espinoza-Quinones, F.R., Zacarlein, C.E., Palacio, S.M., Obregon, C.L., Zenatti, D.C., Galante, R.M., Rossi, N., Rossi, F.L., Pereira, R.A., Welter, R.A., Rizzulto, M.A.(2005): Removal of heavy metals from polluted river using aquatic macrophytes Salvinia sp. Brazilian Journal of Plant Physiology 35, 744-746.

Heike Bradl (2005): Heavy metals in the environment: Origin, Interaction and Remediation, 1st Edn. Academic Press,

Hoffmann, T., Kutter, C., Santamaria, J.M., (2004): Capacity of Salvinia minima Baker to tolerate and accumulate As and $\mathrm{Pb}$. Engineering Life Science 4, 61-65.

Molisani, M.M., Rocha, R., Machado, W., Barreto, R.C., Lacerda, L.D.(2006): Mercury contents in aquatic macrophytes from two resevoirs in the paraiba do sul: Guandu river system, Se Brazil. Brazilian Journal of Biology 66, 101-107.

Mukherjee S., Kumar, S. (2005): Adsorptive uptake of arsenic (V) from water by aquatic fern Salvinia natans. Journal of Water Supply: Research Technology 54, 47-53.

Olguin, J., Hernandez, E., Ramos, I. (2002): The effect of both different light conditions and the $\mathrm{pH}$ value on the capacity of Salvinia minima BAKER for removing cadmium, lead and chromium. Acta Biotechnology 22, 121131.

Olguin E. J., Sa'nchez-Galva'n, G., Pe'rezPe'rez, T., Pe'rez-Orozco, A. (2005): Surface adsorption, intracellular accumulation and compartmentalization of $\mathrm{Pb}$ (II) in batch-operated lagoons with Salvinia minima as affected by environmental conditions, EDTA and nutrients. Journal of Industrial and Microbiology Biotechnology 32, 577586

Rai, U.N., Sinha, S., Tripathi, R.D., Chandra, P., (1995): Wastewater treatability potential of some aquatic macrophytes: removal of heavy metals. Ecological Engineering 5, 5-12.

Schneider, I.A.H., Rubio, J., (1999): Sorption 
of Heavy Metal ions by the nonliving biomass of freshwater macrophytes. Environmental Science and Technology 33, 2213-2217.

Skinner, K., Wright, N., Porter-Goff, E. (2007): Mercury uptake and accumulation by four aquatic plants. Environmental Pollution 145, 234-237.

Sune, N., Sa'nchez, G., Caffaratti, S., Maine, M.A. (2007): Cadmium and chromium removal kinetics from solution by two aquatic macrophytes. Environmental Pollution 145 467-473.

Sweta Kumari, Baidyanath Kumar and Rimjhim Sheel. (2016). Bioremediation of Heavy Metals by Serious Aquatic Weed, Salvinia. Int.J.Curr.Microbiol. App.Sci. 5(9): 355-368. doi: http://dx.doi.org/10.20546/ijcmas.2016. 509.039

\section{How to cite this article:}

Sweta Kumari, Baidyanath Kumar and Rimjhim Sheel. 2017. Biological Control of Heavy Metal Pollutants in Water by Salvinia molesta. Int.J.Curr.Microbiol.App.Sci. 6(4): 2838-2843. doi: https:// doi.org/10.20546/ijcmas.2017.605.325 